\title{
Prediction of Dilution and Its Impact on the Metallurgical and Mechanical Behavior of a Multipass Steel Weldment
}

DOI:

10.1115/1.4044337

\section{Document Version}

Accepted author manuscript

Link to publication record in Manchester Research Explorer

\section{Citation for published version (APA):}

Sun, Y. L., Hamelin, C. J., Flint, T. F., Vasileiou, A. N., Francis, J. A., \& Smith, M. C. (2019). Prediction of Dilution and Its Impact on the Metallurgical and Mechanical Behavior of a Multipass Steel Weldment. Journal of Pressure Vessel Technology, 141(6). https://doi.org/10.1115/1.4044337

\section{Published in:}

Journal of Pressure Vessel Technology

\section{Citing this paper}

Please note that where the full-text provided on Manchester Research Explorer is the Author Accepted Manuscript or Proof version this may differ from the final Published version. If citing, it is advised that you check and use the publisher's definitive version.

\section{General rights}

Copyright and moral rights for the publications made accessible in the Research Explorer are retained by the authors and/or other copyright owners and it is a condition of accessing publications that users recognise and abide by the legal requirements associated with these rights.

\section{Takedown policy}

If you believe that this document breaches copyright please refer to the University of Manchester's Takedown Procedures [http://man.ac.uk/04Y6Bo] or contact uml.scholarlycommunications@manchester.ac.uk providing relevant details, so we can investigate your claim.

\section{OPEN ACCESS}




\title{
Prediction of dilution and its impact on the metallurgical and mechanical behaviour of a multi-pass steel weldment
}

\author{
Y.L. Sun ${ }^{1 *}$, C.J. Hamelin ${ }^{2,3}$, T.F. Flint ${ }^{1}$, A.N. Vasileiou ${ }^{4}$, J.A. Francis ${ }^{1}$, M.C. Smith ${ }^{1}$ \\ ${ }^{1}$ School of Mechanical, Aerospace and Civil Engineering, The University of Manchester, Sackville \\ Street, Manchester M13 9PL, UK \\ ${ }^{2}$ ANSTO, Institute of Materials Engineering, New Illawarra Road, Lucas Heights, NSW \\ 2234, Australia \\ ${ }^{3}$ EDF Energy, Barnett Way, Barnwood, Gloucester GL4 3RS, UK \\ ${ }^{4}$ Dalton Nuclear Institute, The University of Manchester, Oxford Road, M13 9PL UK
}

\begin{abstract}
A three-pass groove weld made by gas-tungsten arc welding in a 20 -mm thick SA508 steel plate is modelled to predict the thermal, metallurgical and mechanical behaviour. The dilution for each pass is estimated as the proportion of base material in the weld metal, based on the predicted crosssectional areas for the fusion zone associated with each individual pass. The temperature predictions are consistent with thermocouple measurement data and cross-weld macrographs. The predicted microstructures are qualitatively compared with the observed microstructures in cross-weld optical micrographs. The measured hardness is then used to quantitatively validate the predictions for postweld micro-constituents (e.g. the ferrite, bainite and martensite fractions), based on a hardnessmicrostructure correlation. The predicted residual stresses are compared with those measured by neutron diffraction. The results show that dilution significantly affects the metallurgical and mechanical properties of weld metal (either as-deposited or reheated), and its consideration notably improves the predictions for microstructure and residual stress in the multi-pass steel weldment. Furthermore, an increase in dilution promotes the formation of martensite, enhances the hardness, and leads to lower tensile stresses (or higher compressive stresses) in the weld metal. Such behaviour arises due to the higher hardenability of the base material employed in this study, coupled with delayed austenite decomposition on cooling.
\end{abstract}

Keywords: Chemical inhomogeneity, Fusion weld, Microstructure, Modelling, Phase transformations, Residual stress.

\footnotetext{
*Correspondence: sunyongletl@gmail.com; yongle.sun@manchester.ac.uk (Y.L. Sun)
} 


\section{Nomenclature}

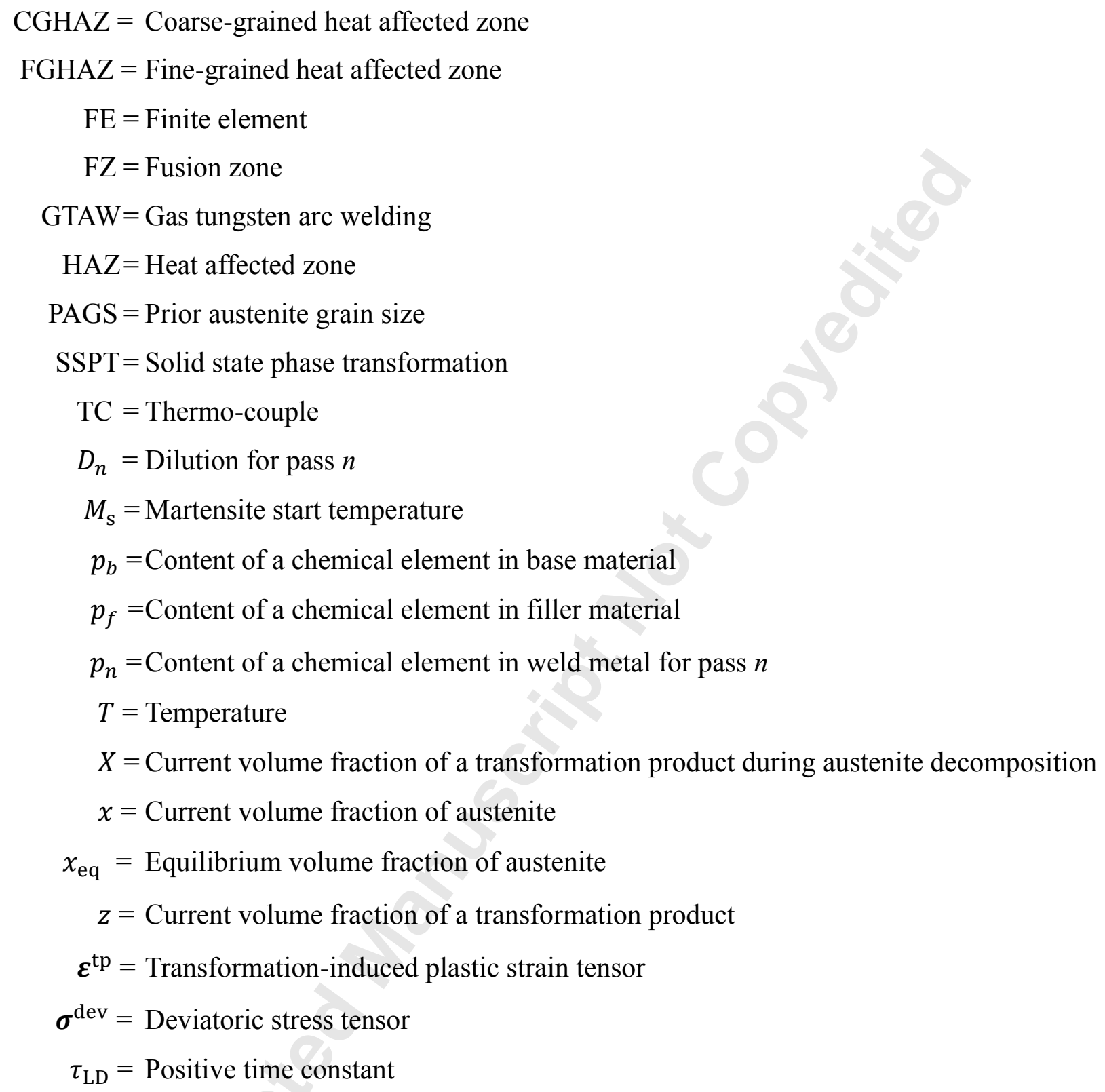

\section{Introduction}

Welding is extensively used in the fabrication of pressure vessels, among other engineering applications, and weldments usually play a critical role in determining the performance and life of these structures [1-3]. Currently, the joining of thick-section components, such as those used in nuclear reactor pressure vessels, relies on multi-pass arc welding [4-7]. It is almost always the case 
that there exists a chemical mismatch between the base and filler materials. Dilution is thus important as it directly affects the chemical composition of weld metal.

Dilution occurs when the filler material mixes with the base material during fusion welding, leading to a weld metal with a chemical composition intermediate between those of the filler and base materials. Dilution is commonly defined as the ratio of the cross-sectional area of melted base material to the total area of the fusion zone [8], hence representing the contribution of base material to the weld metal. Therefore, for a given combination of filler and base materials, the extent of chemical heterogeneity within a weld is influenced by dilution, which can have significant effects on the metallurgical and mechanical behaviour of steel weldments [9-12]. Despite the important role that dilution plays in welding, dilution has not been considered in most published research on multipass weld modelling [13-15]. Further modelling work is thus required to demonstrate predictive capability, and to gain a better understanding of dilution effects.

In this study, a three-pass gas tungsten arc weld in a 20-mm thick low alloy steel (SA508 Gr.3 Cl.1) plate is modelled to investigate the effects of dilution on the metallurgical and mechanical behaviour. A thermal-metallurgical-mechanical model is developed, which considers the distinct dilution values for each pass. The predictions for temperature, microstructure, hardness and residual stress are compared with experimental results reported in previous papers $[16,17]$. The effects of dilution are analysed and discussed.

\section{Materials and methods}

\subsection{Experiment}

Three-pass gas tungsten arc welding (GTAW) was performed on a $200 \mathrm{~mm} \times 150 \mathrm{~mm} \times 20 \mathrm{~mm}$ plate made of SA508 Gr.3 Cl.1 steel. Before welding, a groove was machined along the longitudinal centreline of the plate, to a depth of $6 \mathrm{~mm}$ from the plate surface (Fig. 1). The grooved plate was then 
subjected to a stress relief heat treatment. The final weldment is shown in the right-hand inset of Fig. 1. Table 1 summarises the welding parameters for the three passes, all corresponding to a nominal heat input of $2.0 \mathrm{~kJ} / \mathrm{mm}$. An SD3 filler wire ( $\varnothing 1.2 \mathrm{~mm}$ ) was used during weld bead deposition. An additional grooved plate was also prepared, on which a single weld bead was deposited, using identical process parameters to the first pass of the three-pass weld. This additional plate facilitated the experimental examination of microstructure and residual stress development during the first pass of the welding process. The chemical compositions for the base and filler materials are given in Table 2. The Ito-Bessyo equation [18] was used to calculate the carbon equivalent $\left(\mathrm{C}_{\mathrm{eq}}\right)$, which shows that the base material has a much higher hardenability than the filler material. To measure temperature variations, three sets of four thermo-couples (TC) were attached at different longitudinal positions on the plate surfaces, and the distances between the thermocouples and the weld centreline were kept consistent between each set, as shown in Fig. 1.

Table 1. GTAW process parameters [17]

\begin{tabular}{cccccc}
\hline Pass No. & Voltage (V) & Current (A) & $\begin{array}{c}\text { Torch speed } \\
(\mathrm{mm} / \mathrm{min})\end{array}$ & $\begin{array}{c}\text { Preheat } \\
\left({ }^{\circ} \mathrm{C}\right)\end{array}$ & $\begin{array}{c}\text { Wire feed rate } \\
(\mathrm{mm} / \mathrm{min})\end{array}$ \\
\hline 1 & 11.0 & 227 & 75 & 150 & 1000 \\
2 & 11.5 & 217 & 75 & 150 & 1000 \\
3 & 11.5 & 217 & 75 & 150 & 1000 \\
\hline
\end{tabular}

Table 2. Chemical compositions (wt.\%) for SA508 Gr.3 Cl.1 steel and SD3 filler material [16]

\begin{tabular}{lccccccccc}
\hline & $\mathrm{C}$ & $\mathrm{Si}$ & $\mathrm{Mn}$ & $\mathrm{Ni}$ & $\mathrm{Cr}$ & $\mathrm{Mo}$ & $\mathrm{V}$ & $\mathrm{Fe}$ & $\mathrm{C}_{\mathrm{eq}}$ \\
\hline $\begin{array}{l}\text { SA508 (base } \\
\text { material) }\end{array}$ & 0.2 & 0.25 & 1.4 & 0.8 & 0.2 & 0.5 & 0.003 & Bal. & 0.34 \\
$\begin{array}{l}\text { SD3 (filler } \\
\text { material) }\end{array}$ & 0.08 & 0.3 & 1.4 & 0.03 & 0.04 & 0.01 & - & Bal. & 0.17 \\
\hline
\end{tabular}

Note: $\mathrm{C}_{\mathrm{eq}}=\mathrm{C}+\mathrm{Si} / 30+(\mathrm{Mn}+\mathrm{Cu}+\mathrm{Cr}) / 20+\mathrm{Ni} / 60+\mathrm{Mo} / 15+\mathrm{V} / 10+5 \mathrm{~B}[18]$ is used to calculate the carbon equivalent. 


\subsection{Weld modelling}

The welding process was simulated using a general-purpose finite element (FE) software (i.e. Abaqus), in conjunction with user-defined subroutines. Two-dimensional (2D) simplification of the process was adopted to reduce computational expense, which is acceptable for an informative sensitivity analysis $[19,20]$, and particularly in this case since the weldment has no structural or processing variations along the welding direction. It should be noted that the $2 \mathrm{D}$ weld model was intended to analyse the material behaviour under steady state welding (e.g. at mid-length position), while the start and stop of welding, which are sensitive to the details of operation, were not considered in this study. In addition, a half-model was constructed to take advantage of the symmetry of geometry and process about the weld centreline. Fig. 1 shows the geometry and FE mesh of the weld model. A sequentially coupled modelling approach was employed, i.e. temperature is predicted by a thermal model, providing the basis for subsequent metallurgical predictions, and then the mechanical response is predicted on the basis of the thermal and metallurgical solutions. A series of Abaqus subroutines were defined to apply the heat source and to capture the metallurgical and mechanical behaviour associated with solid state phase transformation (SSPT). The deposition of each weld bead was simulated using the "model change" function (i.e. element birth and death method) in Abaqus. The profiles of the deposited weld beads for the first and third passes were determined from observations in the macrographs for the single-pass and three-pass welded plates in experiment. For the second pass, the weld bead geometry is assumed such that the weld bead occupies equal volume in the groove for each pass, since the torch speed and wire feed rate are identical for the three passes (Table 1). 


\subsubsection{Thermal model}

A thermal model was generated to predict the transient temperature in the weld plate. Firstly, an idealised heat source with ellipsoidal Gaussian volumetric power distribution was employed in a three-dimensional (3D) model defined using a weld modelling package FEAT-WMT [21] for heat source calibration. Table 3 shows the parameters of the heat source which was weaved to obtain optimal thermal solution. Then an equivalent 2D heat source was derived using FEAT-WMT and imported into Abaqus model for its thermal solution, which generated a 2D transient temperature field identical to that on a cross-section under steady-state welding condition within the weld plate modelled in 3D using FEAT-WMT. The Abaqus thermal model comprises 1088 quadratic, quadrilateral elements (Abaqus designation DC2D8) for heat transfer analysis. Convection and radiation on plate surfaces were also considered, for which the convection coefficient, the radiation emissivity and the ambient temperature were taken to be $1 \times 10^{-5} \mathrm{~W} /\left(\mathrm{mm}^{2} \cdot \mathrm{K}\right), 0.4$ and $20{ }^{\circ} \mathrm{C}$, respectively. The thermal properties of the material were obtained from Ref. [22]. The verification of the accuracy of the thermal model was carried out using the temperature histories measured at the prescribed TC locations on the plate surfaces (Fig. 1), as well as the isothermal lines associated with the metallurgical boundaries inferred from macrographs. 


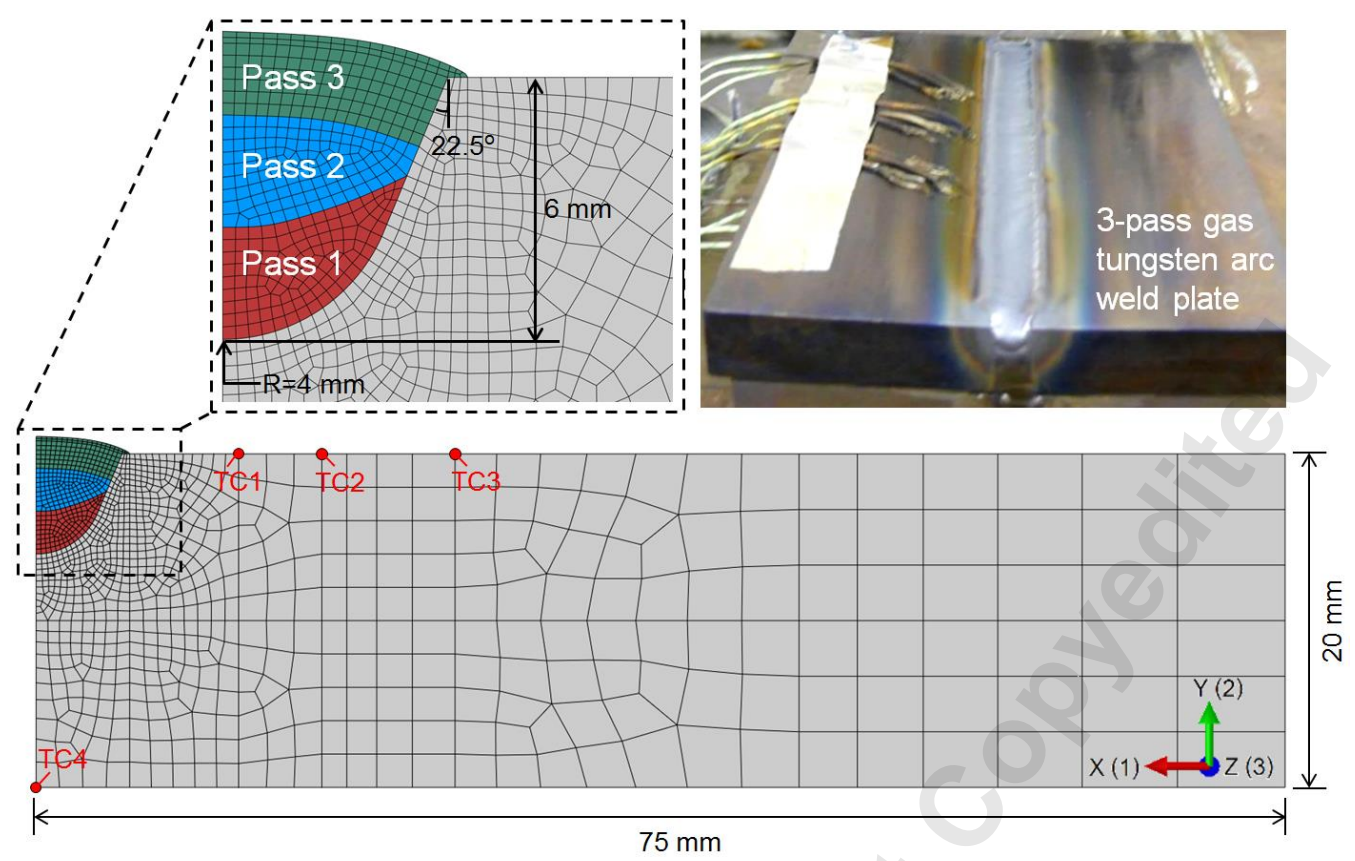

Fig. 1. 2D FE model for simulation of three-pass GTAW in a grooved plate made of SA508 steel (inset). Symmetry about the weld centreline (left) is assumed. The plate length of $200 \mathrm{~mm}$ is considered using a generalised plane strain condition. The locations of four thermocouples (TC1TC4) are also indicated. Note that three sets of four thermocouples at different longitudinal positions but with matching distances from the weld centreline were attached to the plate (inset).

Table 3. Heat source parameters used in the 3D model generated by FEAT-WMT

\begin{tabular}{lllllll}
\hline Pass No. & Efficiency & A-radius & L-radius & V-radius & H-weave & V-weave \\
\hline 1 & 0.81 & 2.5 & 2.4 & 1.1 & $0-2.6$ & $0.5-1.15$ \\
2 & 0.86 & 3.9 & 2.0 & 0.7 & $0-2.0$ & $4.6-1.5$ \\
3 & 0.88 & 5.5 & 2.3 & 0.9 & $0-3.9$ & $2.8-0$ \\
\hline
\end{tabular}

Note: A-, L-, V- and H- denote Axial-, Lateral-, Vertical- and Horizontal-, respectively. Dimensions and positions are in millimeter.

\subsubsection{Metallurgical model}

The impacts of SSPT on mechanical properties and residual stresses in ferritic steel weldments have been widely recognised by both experiments $[23,24]$ and modelling $[15,22,25]$. Here the reaction kinetics of austenite decomposition is modelled on the basis of a semi-empirical approach 
first proposed by Kirkaldy and Venugopalan [26] and later improved by Li et al. [27]. Hamelin et al. [22] have developed a numerical scheme to implement the SSPT kinetics within a weld model using a set of subroutines in Abaqus, and the predictions of weld microstructure and residual stress have been validated for a benchmark, i.e. an autogenous edge-welded beam made of SA508 steel. This numerical scheme is also employed here, with an added capability of considering multiple thermal/metallurgical cycles as well as weld metal dilution. The isothermal transformation for ferrite, pearlite and bainite is governed by the following equation

$$
\tau(X, T)=\frac{F(\mathrm{C}, \mathrm{Mn}, \mathrm{Si}, \mathrm{Ni}, \mathrm{Cr}, \mathrm{Mo}, G)}{\Delta T^{m} \exp (-Q / R T)} S(X)
$$

where $\tau$ is the transformation time required to form a fraction $(X)$ of a specific product; $F$ is a function of the chemical composition (C, Mn, $\mathrm{Si}, \mathrm{Ni}, \mathrm{Cr}$ and $\mathrm{Mo}$ ) and the ASTM number $(G)$ of the prior austenite grain size (PAGS); $S(X)$ is a sigmoidal function; $\Delta T$ is undercooling and $m$ is an empirical exponent; $Q$ is the activation energy for transformation; $T$ is absolute temperature; and $R$ is the universal gas constant. An additivity rule [22] discretising the anisothermal history into a series of isothermal events is used for capturing anisothermal transformation kinetics. The transformation start temperatures for ferrite, pearlite and bainite are all estimated using empirical equations in terms of chemical composition, see Ref. [22] for more details.

The martensite transformation occurring below a critical temperature (i.e. martensite start temperature, $M_{\mathrm{s}}$ ) is modelled using the Koistinen-Marburger equation [28], i.e.

$$
X_{\mathrm{M}}=X_{\mathrm{RA}}\left[1-\exp \left(-A\left(M_{\mathrm{s}}-T\right)\right)\right]
$$


where $X_{\mathrm{M}}$ is the fraction of martensite, $X_{\mathrm{RA}}$ is the fraction of austenite available for martensite transformation and $A$ is a material parameter. The martensite start temperature for full austenite is calculated via $[29,30]$

$$
M_{\mathrm{s}}=539-423 \mathrm{C}-30.4 \mathrm{Mn}-17.7 \mathrm{Ni}-12.1 \mathrm{Cr}-7.5 \mathrm{Mo}+10 \mathrm{Co}-7.5 \mathrm{Si}
$$

where the symbols indicate the weight percentages of the chemical elements. The predicted values of $M_{\mathrm{s}}$ are $390{ }^{\circ} \mathrm{C}$ and $459{ }^{\circ} \mathrm{C}$ for the base material and filler material, respectively. A linear decrease in $M_{\mathrm{s}}$ with the fraction of pre-formed ferrite, pearlite and bainite, if any exists, is also considered [31].

The transformation kinetics of ferrite, pearlite, bainite and martensite, as defined in Eqs. (1)-(3), are all primarily dependent on chemical composition. Therefore, the SSPT of diluted weld metal upon cooling is complicated due to the mixture of the base and filler materials (Table 2). A rule-ofmixtures is applied here to estimate the chemical composition of the diluted weld metal, viz.

$$
p_{n}=p_{\mathrm{b}} D_{n}+p_{\mathrm{f}}\left(1-D_{n}\right)
$$

where $p_{n}$ is the content of a chemical element for pass $n ; p_{\mathrm{b}}$ and $p_{\mathrm{f}}$ are the contents of the element in the base material and filler material, respectively; $D_{n}$ is the dilution for pass $n$. The dilution is assessed by calculating the ratio of the fusion area of the base material to that of the weld metal. The predicted fusion zone (FZ) for each pass is used in the estimation of dilution here, while measured fusion area can be used if macrographs of fusion zones for all three passes are available in experiment, which, unfortunately, is not the case in this study.

For austenite formation upon heating, the empirical approach proposed by Leblond and Devaux [32] is employed to capture the kinetics. The growth rate of austenitic phase is expressed as follows

$$
\dot{x}=\frac{x_{\mathrm{eq}}-x}{\tau_{\mathrm{LD}}}
$$


where $x_{\mathrm{eq}}$ and $\tau_{\mathrm{LD}}$ are the equilibrium austenite fraction and a positive time constant, respectively. Table 4 presents the values of $x_{\mathrm{eq}}$ and $\tau_{\mathrm{LD}}$ adopted in the weld model. The characteristic temperatures of $760{ }^{\circ} \mathrm{C}$ and $830{ }^{\circ} \mathrm{C}$ (Table 3) are the $\mathrm{A}_{\mathrm{c} 1}$ and $\mathrm{A}_{\mathrm{c} 3}$ temperatures of the SA508 steel when it is heated slowly $[31,33]$. For heating beyond melting point $\left(T_{\mathrm{m}}=1450{ }^{\circ} \mathrm{C}[22]\right)$, it is assumed that the $\mathrm{FZ}$ is fully austenitised once temperature drops below $T_{\mathrm{m}}$.

Austenite grain growth in the heat affected zone (HAZ) is captured with consideration of two situations: (1) a limit on the grain size is imposed if the peak temperature is lower than a grain coarsening temperature $\left(T_{\mathrm{c}}=1020{ }^{\circ} \mathrm{C}\right)$ and the grain growth model by Pous-Romero et al. [33] is adopted; (2) the limit on the grain size vanishes if the peak temperature is higher than $T_{\mathrm{c}}$. A constant PAGS equal to $0.4 \mathrm{~mm}$ is assumed for columnar grains in the $\mathrm{FZ}$, as estimated from the $\mathrm{FZ}$ micrographs presented in Ref. [16].

Table 4. Temperature-dependent parameters used in the austenitisation kinetics model (Eq. 5). Note that $x_{\mathrm{eq}}$ and $\tau_{\mathrm{LD}}$ are linearly interpolated between 760 and $830^{\circ} \mathrm{C}$.

\begin{tabular}{ccc}
\hline Temperature $\left({ }^{\circ} \mathrm{C}\right)$ & $x_{\mathrm{eq}}$ & $\tau_{\mathrm{LD}}(\mathrm{s})$ \\
\hline$<760$ & 0 & 1 \\
760 & 0 & 1 \\
830 & 1 & 0.2 \\
$>830$ & 1 & 0.05 \\
\hline
\end{tabular}

Weld microstructure can be correlated with micro-hardness and the correlation is widely used to validate the prediction about the fractions of different micro-constituents in the final weld $[22,34]$. The microstructure-hardness correlation is based on a rule-of-mixtures, i.e. 


$$
H v=H v_{\mathrm{M}} X_{\mathrm{M}}+H v_{\mathrm{B}} X_{\mathrm{B}}+H v_{\mathrm{F} / \mathrm{P}} X_{\mathrm{F} / \mathrm{P}}\left(X_{\mathrm{F}}+X_{\mathrm{P}}\right)+H v_{\mathrm{A}} X_{\mathrm{A}}+H v_{\mathrm{b} 0} X_{\mathrm{b} 0}
$$

where $H v, H v_{\mathrm{M}}, H v_{\mathrm{B}}, H v_{\mathrm{F} / \mathrm{P}}, H v_{\mathrm{A}}$ and $H v_{\mathrm{b} 0}$ are the Vickers micro-hardness of the whole mixture, martensite, bainite, ferrite (or pearlite), austenite and base material, respectively; $X_{\mathrm{M}}, X_{\mathrm{B}}, X_{\mathrm{F}}, X_{\mathrm{P}}, X_{\mathrm{A}}$ and $X_{\mathrm{b} 0}$ are the fractions of martensite, bainite, ferrite, pearlite, austenite and base material, respectively. For each ferritic phase, empirical hardness equations in terms of chemical composition and cooling rate are used [22]. The hardness of base material and retained austenite are taken to be $200 \mathrm{HV}$ and $160 \mathrm{HV}$, respectively [22].

\subsubsection{Mechanical model}

The thermal-metallurgical deformation upon temperature variation acts as the driving force to generate stress in the weldment. The thermal-metallurgical strain is decomposed into two parts: volumetric strain and plastic strain. The volumetric strain is taken into account by employing a ruleof-mixtures based on the dilatometry data for SA508 Gr.3 Cl.1 steel (ferritic and austenitic phases are decoupled) [22], while the transformation-induced plastic strain is estimated using the model proposed by Leblond et al. [35], as expressed below

$$
\dot{\boldsymbol{\varepsilon}}^{\mathrm{tp}}=3 K \boldsymbol{\sigma}^{\mathrm{dev}}(1-z) \dot{Z}
$$

where $\boldsymbol{\sigma}^{\mathrm{dev}}$ is the deviatoric stress tensor, $\dot{z}$ is the phase transformation rate and $K$ is a material constant $\left(\approx 10^{-4} \mathrm{MPa}^{-1}\right.$ for SA508 steel [35]).

The mechanical model comprises 1088 quadratic, quadrilateral, generalised plane strain, hybrid elements (Abaqus designation CPEG8H), which share the same nodal coordinates as those in the thermal model. A symmetrical boundary condition is applied on the weld centreline throughout thickness, and the bottom corner node on the symmetry plane is fully fixed. Temperature- and phasedependent material properties are considered to capture the elastic-plastic behaviour of the 
weldment. Kinematic hardening is assumed in the plasticity model. The material parameters reported in Ref. [22] are adopted in the mechanical model.

\section{Results and discussion}

\subsection{Temperature and dilution}

Fig. 2a-c shows the comparison between the predicted and measured temperature histories at four TC locations (Fig. 1). For each TC location, three sets of test data are presented, which correspond to the same distance from weld centreline but different longitudinal positions (inset in Fig. 1). There is some scatter between the three sets of TC measurement data, although they are expected to be identical in terms of peak temperature under ideal steady state of welding. The rise in temperature is also examined, as shown in Fig. 2d, and the root mean square errors of the prediction are $9.6 \%, 9.0 \%$ and $8.3 \%$ for the first pass, second pass and third pass, respectively, in comparison with the averaged measurements between the three sets of TC data. It is evident that the predictions are in overall good agreement with the measurements. Based on the thermal model, the cooling rates at $700{ }^{\circ} \mathrm{C}$ in both the $\mathrm{FZ}$ and $\mathrm{HAZ}$ are calculated, which are $28 \pm 2,26 \pm 2$ and $26 \pm 3{ }^{\circ} \mathrm{C} / \mathrm{s}$ for the first pass, second pass and third pass, respectively. Although no temperature measurements were implemented in the FZ and HAZ, the predicted cooling rates in the FZ and HAZ are deemed representative, since the predicted histories of temperature on the plate surfaces have been validated by experimental measurements (Fig. 2). It is also noted that the predicted cooling rate is similar at different locations within the FZ and HAZ, and it only changes slightly between different passes. 

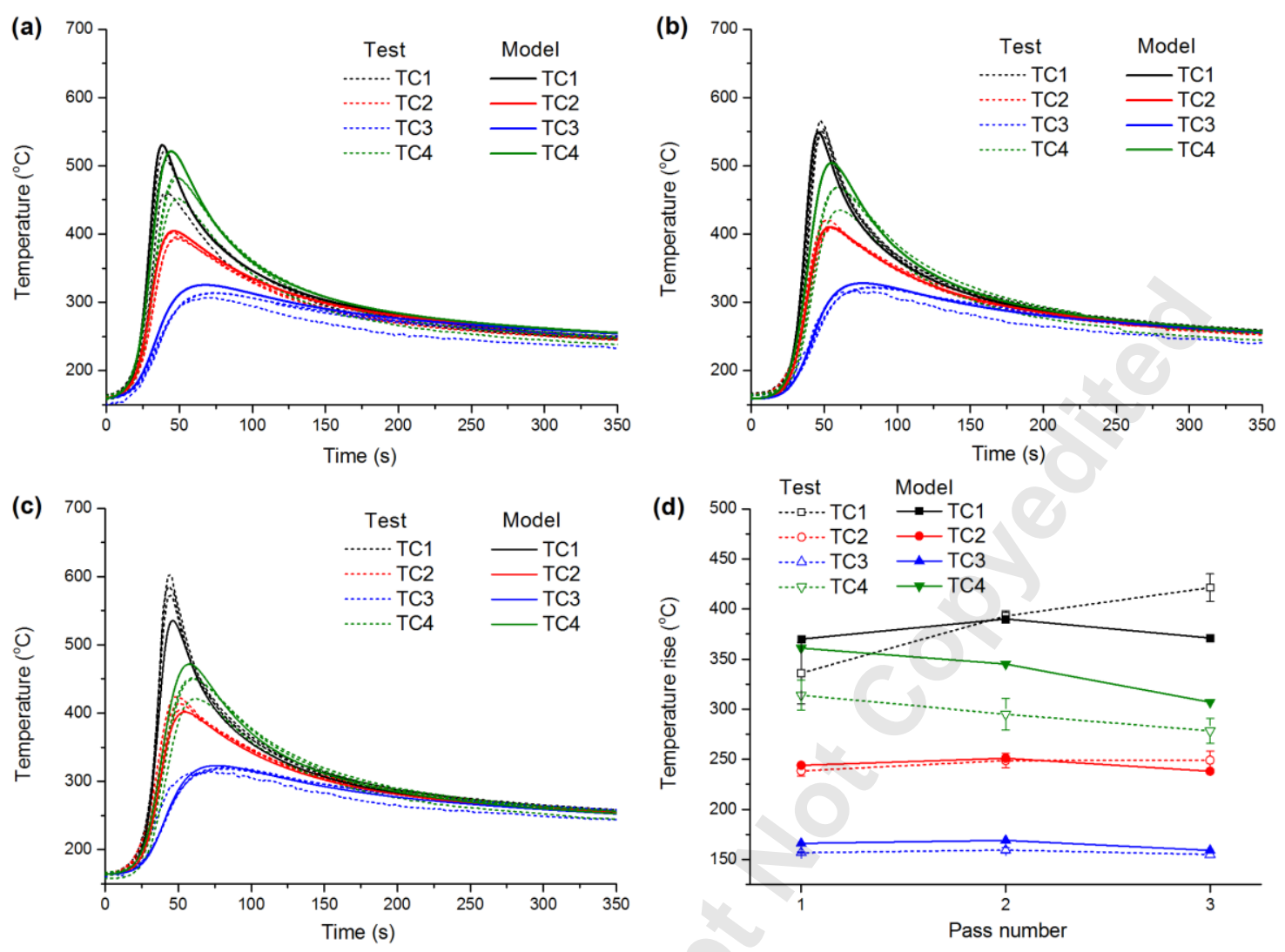

Fig. 2. Comparison between the predicted and measured temperature histories at four TC locations (Fig. 1): (a) first pass; (b) second pass; (c) third pass. Note that three sets of four thermocouples at different longitudinal positions but with matching distances from the weld centreline were attached to the plate [16] and the time is relative to the start of each pass. The temperature rise for each pass, as calculated from the prediction and measurement, is also shown in (d).

Fig. 3 shows the predicted peak temperature distributions, in comparison with the metallurgical zones as observed in macrographs. Four characteristic temperatures, i.e. $1450,1020,830$ and $760{ }^{\circ} \mathrm{C}$, represent melting, grain coarsening, $A_{c 3}$ and $A_{c 1}$ temperatures, respectively [12]. The related isothermal lines are used to indicate the boundaries of the FZ, coarse-grained HAZ (CGHAZ), finegrained HAZ (FGHAZ) and inter-critical HAZ (ICHAZ). It is observed that the isothermal lines which are identifiable from the macrographs have been captured in the thermal model and the error of predicted fusion area is less than $8 \%$, as shown in Table 5 . These results further confirm that the thermal solution is accurate. The predicted peak temperatures in different metallurgical zones (e.g. 
FZ, CGHAZ and FGHAZ), along with the estimated cooling rates, provide the thermal conditions affecting SSPT and therefore determine the microstructures across the weldment.
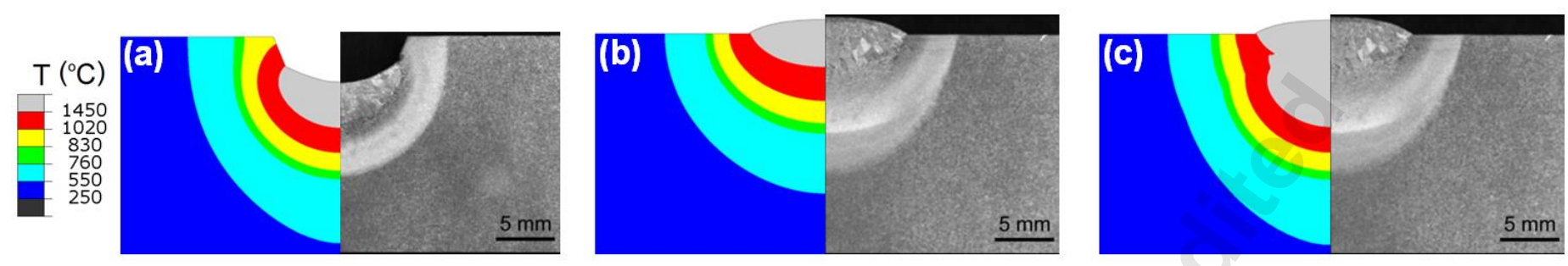

Fig. 3. Distributions of peak temperatures for first pass (a), third pass (b) and all three passes (c). The macrographs [17] for the one-pass welded plate (a) and three-pass welded plate (b, c) are also shown.

Table 5. Measured and predicted fusion areas $\left(\mathrm{mm}^{2}\right)$

\begin{tabular}{cccc}
\hline Pass No. & Measurement & Prediction & Difference \\
\hline 1 & 27.7 & 29.7 & $7.2 \%$ \\
3 & 31.0 & 30.9 & $0.3 \%$ \\
\hline
\end{tabular}

Fig. 4 shows the determination of dilution for each pass. The predicted FZ is compared with the original groove geometry, such that the contribution of base material to the weld metal can be calculated, i.e. the ratio of the melted base material area to the fusion area is taken to be the dilution. It should be noted that the re-melting of previously formed weld metal (Fig. $4 \mathrm{~b}$ and $4 \mathrm{c}$ ) has been taken into account when calculating dilution, viz.

$$
D_{i}=D_{i}^{\mathrm{b}}+\sum_{k=1}^{i-1} D_{k} D_{i-k}^{\mathrm{w}}
$$

where $D_{i}$ is the dilution for pass $i, D_{i}^{\mathrm{b}}$ is the ratio of the melted base-material area to the fusion area for pass $i$, and $D_{i-k}^{\mathrm{w}}$ is the ratio of the re-melted weld metal for pass $k$ to the fusion area for pass $i$, which is pertinent when $i \geq 2$. Fig. $4 \mathrm{~d}$ shows the predicted dilution, of which the accuracy is consistent with that of the FZ prediction (predicted FZ agrees well with experimental observations, 
see Fig. 3 and Table 5). Unsurprisingly, the dilution reduces with subsequent passes, i.e. the predicted dilution is $0.44,0.17$ and 0.09 for the first pass, second pass and third pass, respectively.
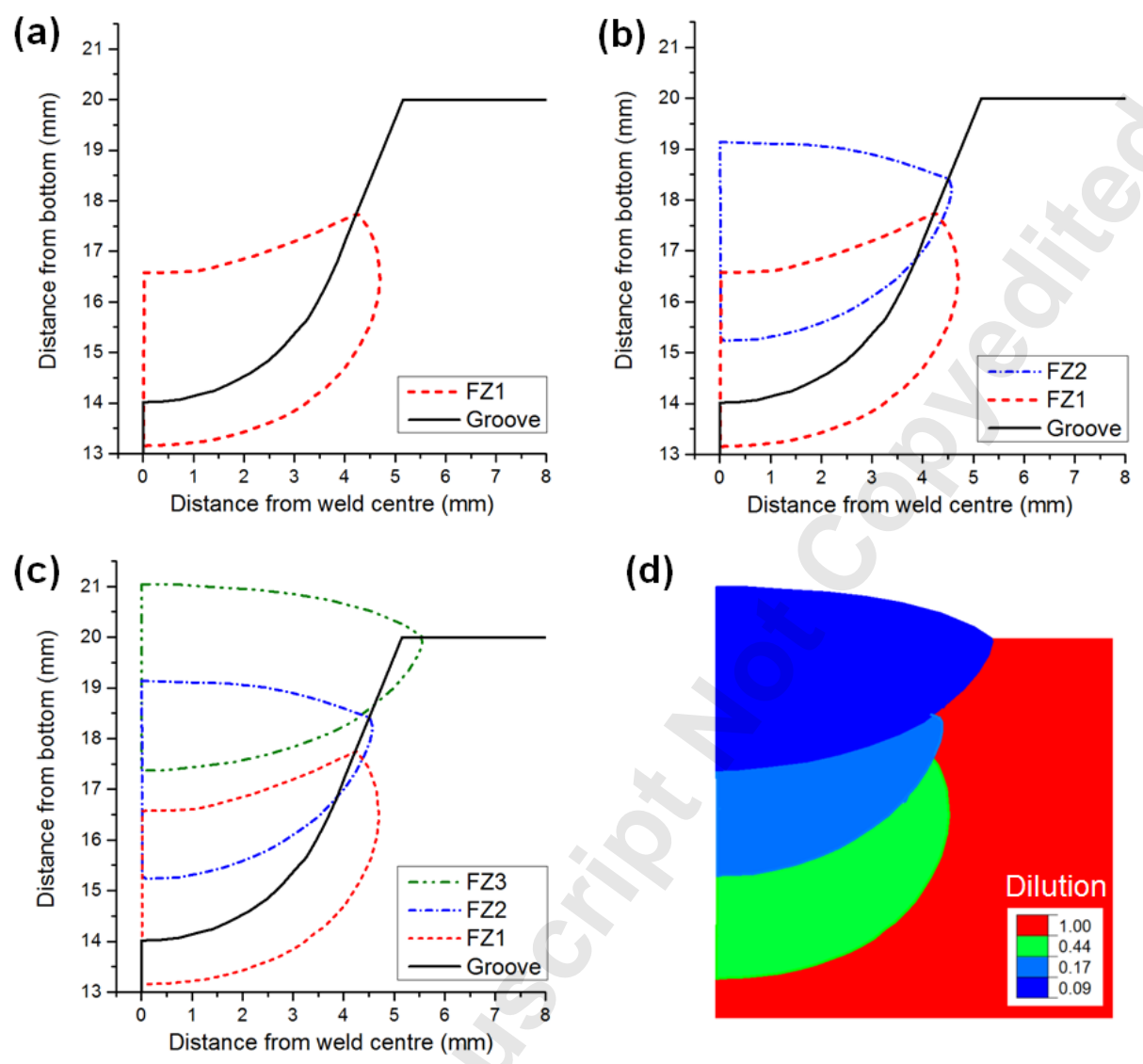

(d)

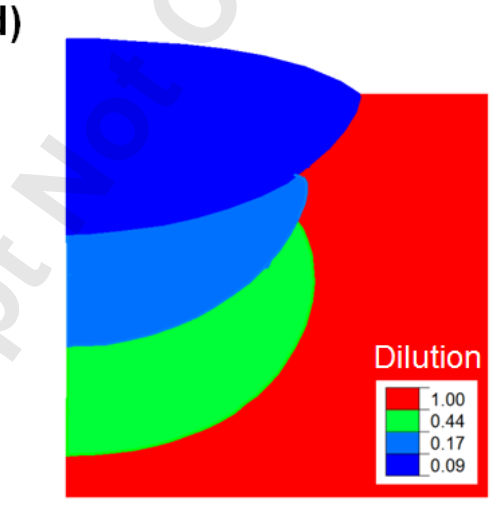

Fig. 4. Determination of dilution based on the predicted fusion areas: (a) after one pass; (b) after two passes; (c) after three passes; and (d) dilution in the three-pass weld. Note that FZ1, FZ2 and FZ3 denote the fusion zones produced by first pass, second pass and third pass, respectively.

\subsection{Microstructure and hardness}

The microstructures in the FZ and HAZ, as observed in optical micrographs, are shown in Fig. 5. The weld metal microstructure exhibits a morphological feature typical of acicular ferrite, i.e. chaotic arrangement of elongated ferrite grains in a cross-weave pattern, as shown in Fig. 5a. Moreover, fine martensite and bainite are observed, which are also confirmed through hardness measurements [16]. As acicular ferrite is widely regarded as intragranularly nucleated bainite [36], for the sake of simplicity, acicular ferrite is treated as being equivalent to bainite in the current SSPT model. More 
sophisticated transformation kinetics for acicular ferrite will be considered in future work. The CGHAZ formed in the base material comprises a mixture of martensite and bainite (Fig. 5b), while the FGHAZ is dominated by bainite (Fig. 5c).
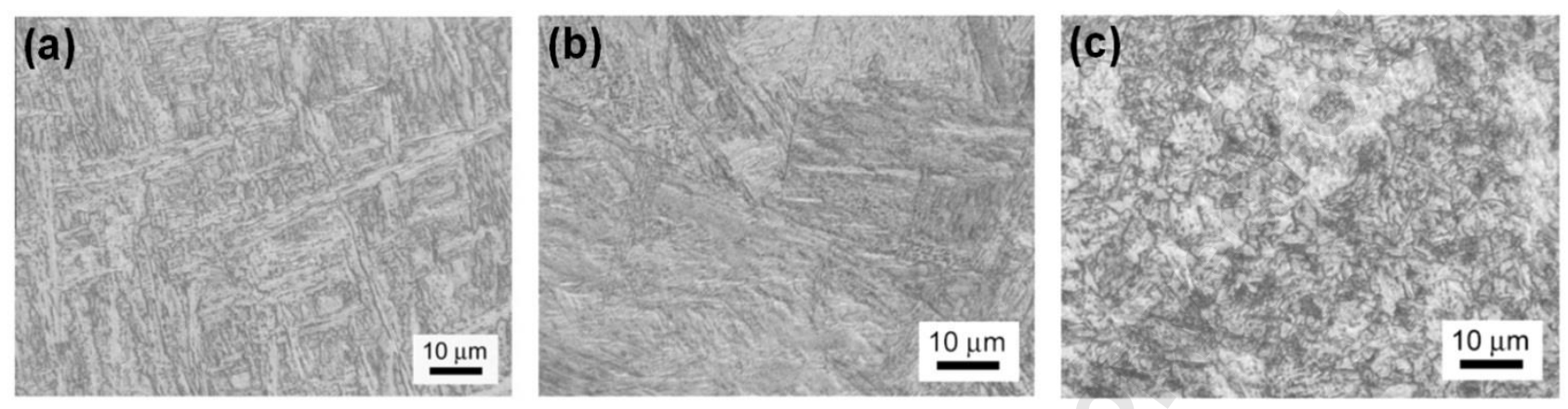

Fig. 5. Optical micrographs [16] showing the microstructures in the weldment: (a) FZ (as-deposited weld metal); (b) CGHAZ (formed in base material); (c) FGHAZ (formed in base material).

Three cases related to weld metal are considered in the SSPT modelling: (1) actual dilution (Fig. $4 d$ ), as determined from the thermal model, i.e. $D_{1}=0.44, D_{2}=0.17, D_{3}=0.09$; (b) assumed base material, i.e. $\mathrm{D}_{1}=\mathrm{D}_{2}=\mathrm{D}_{3}=1$; and (c) assumed filler material, i.e. $\mathrm{D}_{1}=\mathrm{D}_{2}=\mathrm{D}_{3}=0$. The predictions about the fractions of martensite, bainite and ferrite are shown in Figs. 6, 7 and 8, respectively. No pearlite was predicted and negligible austenite was retained. The predicted microstructure is qualitatively consistent with the microscopic observation (Fig. 5) when actual dilution is considered.

For the one-pass weldment, dilution only affects the microstructure of the as-deposited weld metal (i.e. FZ formed in the current pass). It is clearly seen that dilution promotes the formation of martensite in weld metal. This is because the base material has a much higher hardenability than the filler material (Table 2), and higher dilution leads to a greater contribution of base material to the weld metal. After two passes or three passes, the effects of dilution on reheated weld metal (i.e. HAZ formed in previous FZ) become pronounced, i.e. the microstructure is different between the HAZ located in the base material and that in the reheated weld metal (Figs. 6a, 7a and 8a). In general, the 
base material CGHAZ comprises a mixture of martensite and bainite, while the CGHAZ formed in the reheated weld metal is mainly composed of bainite. Bainite is also dominant in the base material FGHAZ, but ferrite can be present in the FGHAZ located in the reheated weld metal (Fig. 8a). When the chemical composition of the weld metal is assumed to be identical to the base material $\left(D_{1}=D_{2}=\right.$ $D_{3}=1$ ), these microstructural differences no longer exist (Figs. $6 b, 7 b$ and $8 b$ ). As the actual dilution reduces with subsequent passes (i.e. $0.44,0.17$ and 0.09 for first pass, second pass and third pass, respectively, see Fig. 4d), the as-deposited weld metal of the third pass has a microstructure dominated by bainite, in contrast to the mixture of martensite and bainite for first pass (Figs. 6a, 7a and 8a). It is also noteworthy that the martensite formed underneath the FZ after the first pass, which was located in base material CGHAZ, re-transformed to bainite after the second pass. This is because of the differences in austenitising thermal cycles at the same location, i.e. the high peak temperatures and cooling rates associated with the CGHAZ formed in the base material for the first pass were replaced by lower peak temperatures and cooling rates associated with the FGHAZ during the second pass.

The predicted sensitivity of microstructure to dilution (Figs. 6-8) shows that increasing dilution leads to higher fractions of martensite in both as-deposited and reheated weld metals. Accordingly, high dilution suppresses the tendency of the formation of bainite and ferrite in weld metal. As aforementioned, this metallurgical behaviour results from the higher hardenability of the base material $\left(\mathrm{C}_{\mathrm{eq}}=0.34\right)$ in comparison with the filler material $\left(\mathrm{C}_{\mathrm{eq}}=0.17\right)$. The role of the base material playing in affecting weld metal SSPT is enhanced as the dilution increases. 


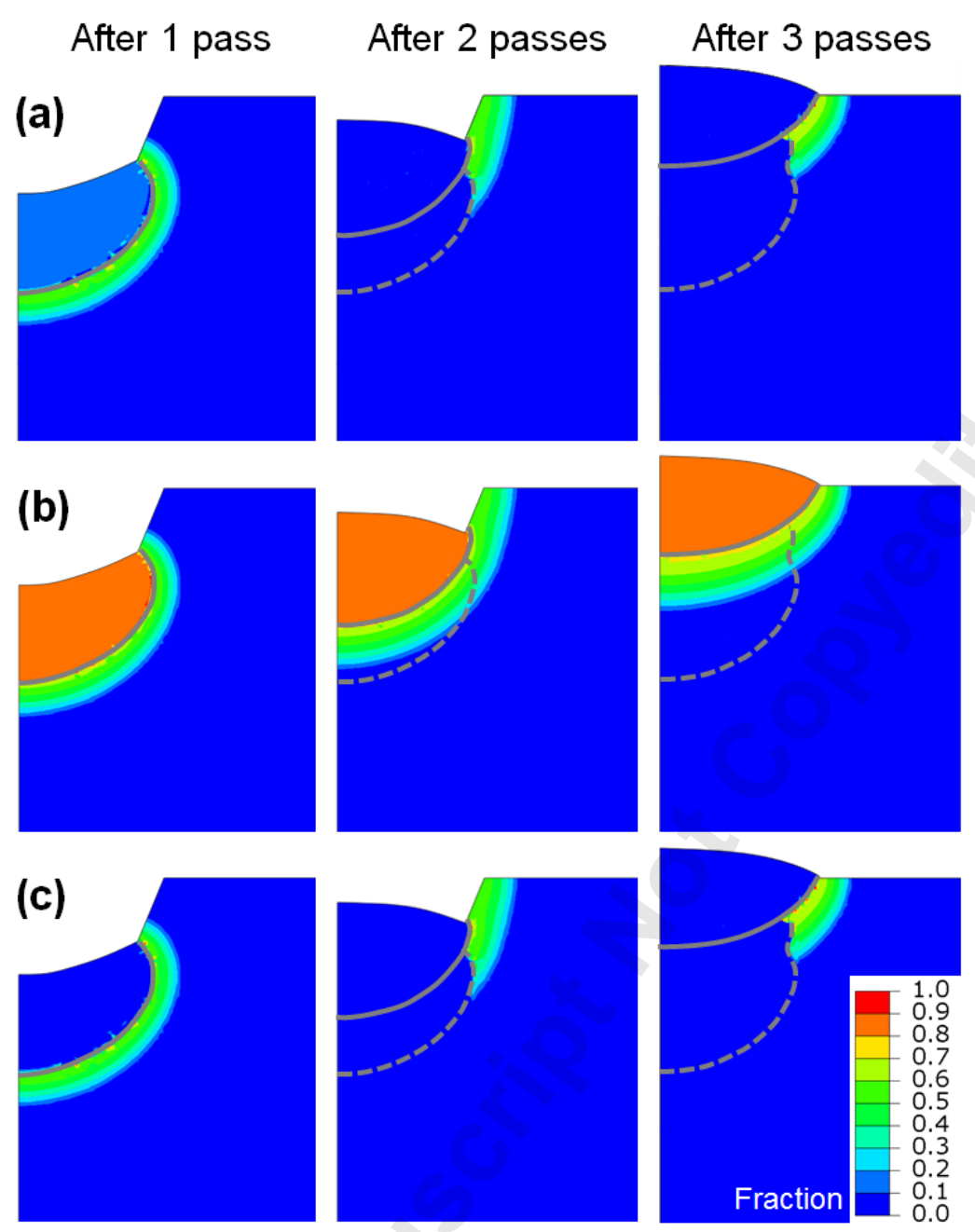

Fig. 6. Predicted martensite fraction in the weldment: (a) $\mathrm{D}_{1}=0.44, \mathrm{D}_{2}=0.17, \mathrm{D}_{3}=0.09$; (b) $\mathrm{D}_{1}=\mathrm{D}_{2}$ $=\mathrm{D}_{3}=1$; (c) $\mathrm{D}_{1}=\mathrm{D}_{2}=\mathrm{D}_{3}=0$. Solid and dashed grey lines indicate the current and accumulated fusion boundaries, respectively. 

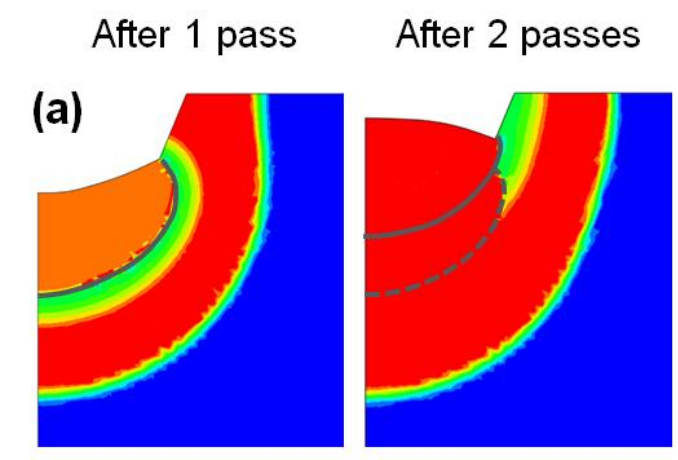

After 3 passes


Fig. 7. Predicted bainite fraction in the weldment: (a) $\mathrm{D}_{1}=0.44, \mathrm{D}_{2}=0.17, \mathrm{D}_{3}=0.09$; (b) $\mathrm{D}_{1}=\mathrm{D}_{2}=$ $\mathrm{D}_{3}=1$; (c) $\mathrm{D}_{1}=\mathrm{D}_{2}=\mathrm{D}_{3}=0$. Solid and dashed grey lines indicate the current and accumulated fusion boundaries, respectively. 

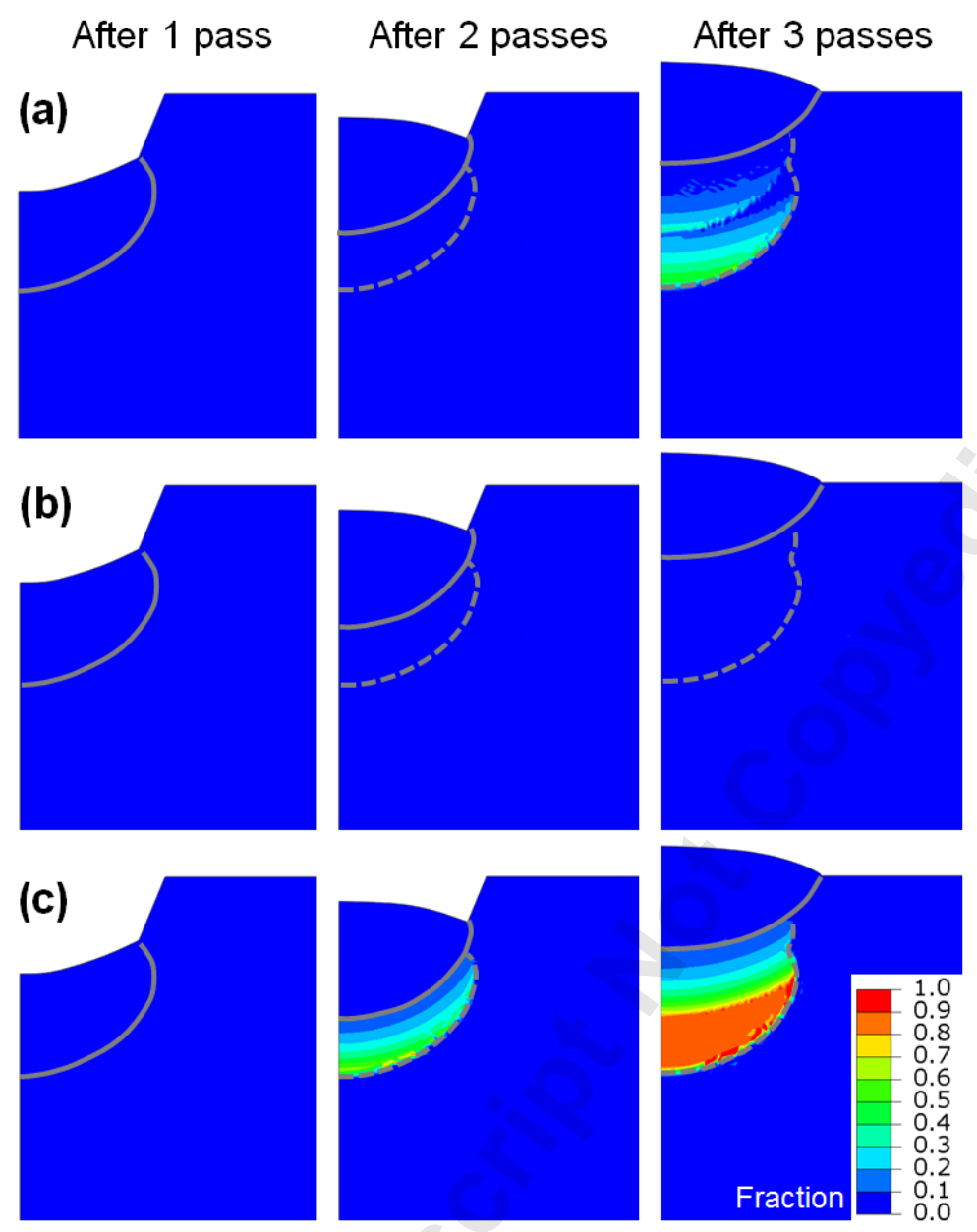

Fig. 8. Predicted ferrite fraction in the weldment: (a) $\mathrm{D}_{1}=0.44, \mathrm{D}_{2}=0.17, \mathrm{D}_{3}=0.09$; (b) $\mathrm{D}_{1}=\mathrm{D}_{2}=$ $\mathrm{D}_{3}=1$; (c) $\mathrm{D}_{1}=\mathrm{D}_{2}=\mathrm{D}_{3}=0$. Solid and dashed grey lines indicate the current and accumulated fusion boundaries, respectively.

Fig. 9 presents the predicted Vickers micro-hardness distributions in the weldment after different passes. It is manifest that the hardness of weld metal with dilution equal to one is much higher than that with dilution equal to zero. For actual dilution, when the weld metal is reheated during second and third passes, elevated hardness is found only in the base material HAZ adjacent to the FZ along the transverse direction (through width), whereas the hardness is much lower in the reheated weld metal HAZ adjacent to the FZ along the vertical direction (through thickness). These features of the hardness distribution are consistent with the developed microstructure (Figs. 5-8) after each pass. It should be noted that the potential effect of tempering on the hardness is limited in this study, since 
extensive re-austenitisation and re-transformation have occurred in the region where martensite fraction is considerable (Figs. 6-8) [37]. The predicted hardness is also compared with experimental test data [16]. The Vickers hardness was measured using an Instron/Wilson Tukon 2100 tester, with a $0.5 \mathrm{~kg}$ load and at intervals of $0.25 \mathrm{~mm}$ along different linear paths [16]. These line profiles of hardness are deemed representative for the inspected region, despite the potential effect of heterogeneous microstructure on scatter in hardness measurement. Fig. 10 shows the vertical and transverse line plots of hardness. It is clearly seen that the hardness predictions are in overall good agreement with the measurements when actual dilution is considered in modelling. This agreement provides a quantitative validation of the metallurgical model. It shows that the assumptions of dilution equal to one (i.e. base material) and zero (i.e. filler material) cause significant overestimates and underestimates of the weld metal hardness, respectively. 

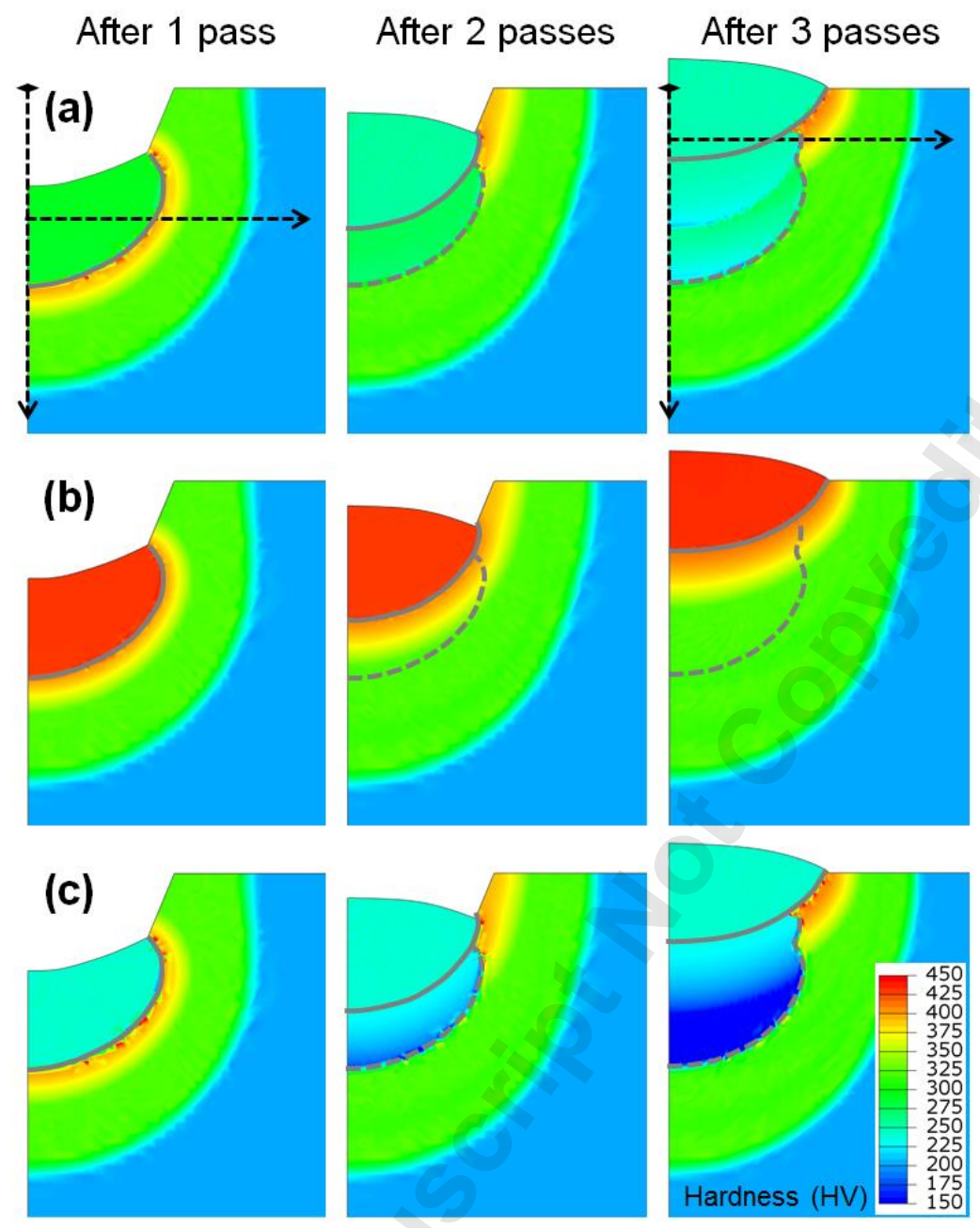

Fig. 9. Predicted hardness distribution in the weldment: (a) $\mathrm{D}_{1}=0.44, \mathrm{D}_{2}=0.17, \mathrm{D}_{3}=0.09$; (b) $\mathrm{D}_{1}=$ $D_{2}=D_{3}=1$; (c) $D_{1}=D_{2}=D_{3}=0$. Solid and dashed grey lines indicate the current and accumulated fusion boundaries, respectively. The dashed arrows show the paths for line plots in Fig. 10. 

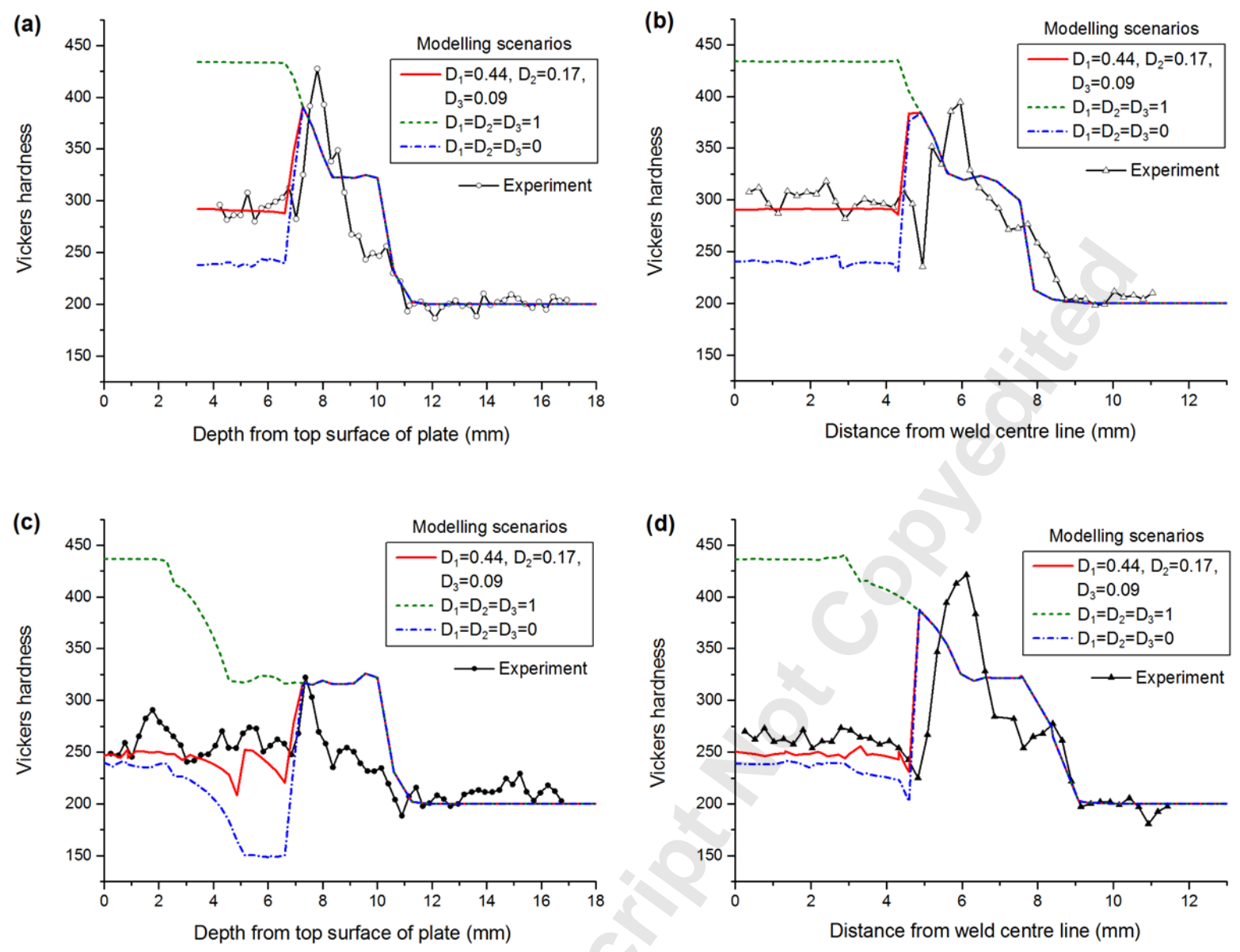

Fig. 10. Predicted and measured line profiles of hardness: (a) vertical distribution after one pass; (b) transverse distribution after one pass; (c) vertical distribution after three passes; (d) transverse distribution after three passes. The paths for line plots are shown in Fig. 9. The experimental results are obtained from Ref. [16].

\subsection{Residual stress}

Fig. 11 shows the through-thickness distributions of predicted residual stresses on the weld centreline. For both the one-pass and three-pass weld cases, the welded plate is finally cooled to room temperature (i.e. $20^{\circ} \mathrm{C}$ ). The numerical predictions and experimental measurements of residual stresses are also compared in Fig. 11. The residual stress measurements were performed using the neutron diffraction method at the FRM II neutron source in Germany; a nominal gauge volume of $2 \times 2 \times 2 \mathrm{~mm}^{3}$ was used while interrogating the $\{211\}$ crystal reflection [16]. The comparison shows 
that the transverse stresses can be relatively accurately captured by the 2D model with a generalised plane strain assumption. However, the prediction of longitudinal stresses is less accurate. For the one-pass weldment, the tensile longitudinal stresses are underestimated while the compressive longitudinal stresses are overestimated. For the three-pass weldment, the neutron diffraction measurements show significant tensile longitudinal stresses in the third-pass FZ, in contrast to the predicted compressive stresses. The accuracy of stress prediction is affected by the $2 \mathrm{D}$ simplification, which leads to over-constraint of the deformation in the longitudinal direction. Furthermore, the temperature- and phase-dependent material properties adopted in the weld model are assumed same as those of SA508 steel and its different transformation products [22], which may not be fully representative for a weld metal comprising a mixture of SA508 steel and SD3 filler (Table 2). Mark et al. [16] report significant differences in the yield stress and tensile stress-strain curves, for weld metal and base material undergoing similar thermal cycles. In addition, the uncertainty in mechanical properties for weld metal has a larger impact on the three-pass weld residual stresses since the weld metal accounts for a greater volume in comparison with the one-pass weld. This may explain the reduced accuracy of predicted transverse residual stresses in the three-pass weld. Despite some discrepancies, it is deemed that the accuracy that is achieved is sufficient for an informative and qualitative sensitivity study of the effects of dilution. 

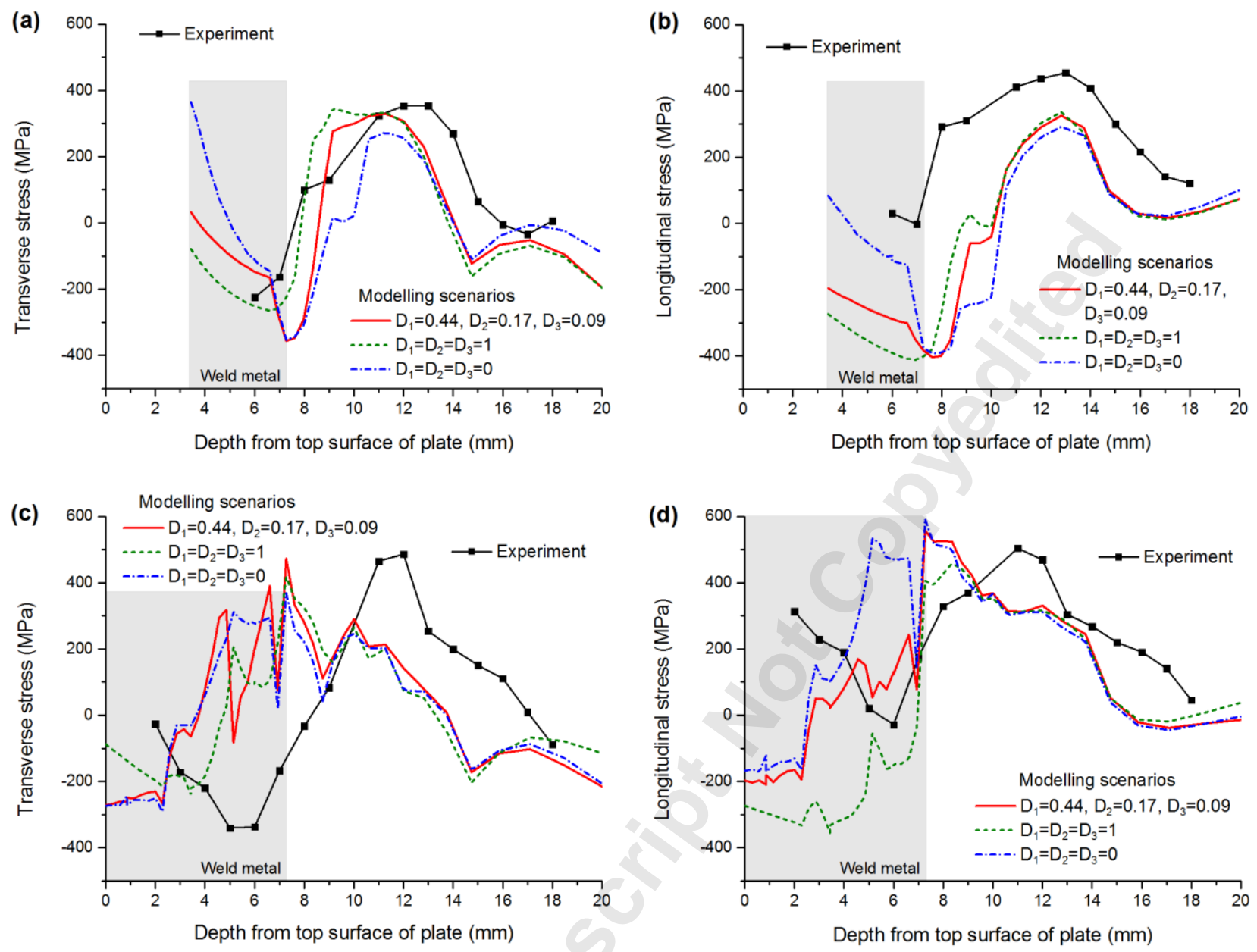

Fig. 11. Predicted and measured through-thickness distributions of residual stresses: (a) transverse stress after one pass; (b) longitudinal stress after one pass; (c) transverse stress after three passes; (d) longitudinal stress after three passes. The experimental neutron diffraction measurement results are taken from Ref. [16].

The effects of dilution on the residual stresses in the one-pass weldment are clear (Fig. 11a and 11b), i.e. the transverse and longitudinal stresses in the weld metal tend to be less tensile or more compressive with higher dilution, causing an equilibrating increase in tensile stress in the HAZ and the adjacent base material. This is because more martensite can be formed in weld metal with increasing dilution (Fig. 6), and the associated relatively low temperature transformation generates a transformation strain which can counteract the thermal contraction (responsible for tensile stress) during cooling, thereby leading to lower tensile or higher compressive stresses in the final weldment. 
Also, for the considered base and filler materials, the dilution reduces the start and finish temperatures for both martensite and bainite transformations in the weld metal, thereby enhancing the efficacy of the associated deformation compensation during cooling towards room temperature. These mechanisms have been also confirmed in experiments [24, 38].

The residual stresses in the three-pass weldment are complicated, as shown in Fig. 11c and 11d. Significant fluctuations in predicted stresses are present in the weld metal, which can be attributed to the highly heterogeneous microstructures predicted in the weld metal, particularly when (1) $\mathrm{D}_{1}=$ 0.44, $\mathrm{D}_{2}=0.17, \mathrm{D}_{3}=0.09$ and (2) $\mathrm{D}_{1}=\mathrm{D}_{2}=\mathrm{D}_{3}=0$ (Figs. 6-8). Unsurprisingly, increasing dilution causes the stresses to be less tensile or more compressive in the weld metal, except for the transverse stresses close to the top surface. During the third pass, a considerable amount of ferrite forms in the reheated weld metal for actual dilution (Fig. 8), despite the overall dominance of bainite (Fig. 7). The formation of ferrite and bainite at relatively high temperatures has less impact on residual stress development, since the thermal contraction accumulated between the transformation finish temperature and room temperature is still significant. In other words, the thermal contraction still plays a major role in the determination of residual stresses. In contrast, the martensite transformation starts at relatively low temperatures and the transformation strains are introduced closer to room temperature, thereby more effectively compensating the thermal contraction. This also implies that lowering the finish temperature for austenite decomposition, as realised via increasing dilution in this case, is beneficial for reducing tensile stress.

Fig. 12 shows the predicted residual stress distributions after one pass. It is found that, with higher dilution, both transverse and longitudinal stresses are enhanced overall, and the high tensile stress region around the HAZ boundary is enlarged. This dilution effect may be detrimental to the structural integrity of the HAZ. However, for the weld metal, the reduced tensile stresses (or 
enhanced compressive stresses) and the enlarged regions under compression at higher dilution levels are likely to be beneficial to the structural performance. Fig. 13 shows the predicted residual stress distribution in the three-pass weldment. It is interesting to note that high compressive longitudinal stresses are concentrated in a region beside the FZ, when $\mathrm{D}_{1}=0.44, \mathrm{D}_{2}=0.17, \mathrm{D}_{3}=0.09$ or $\mathrm{D}_{1}=\mathrm{D}_{2}=$ $\mathrm{D}_{3}=0$. In the same region, the compressive stress levels are lower but the compressed region extends to the weld metal when $D_{1}=D_{2}=D_{3}=1$. This stress feature is associated with the martensite distributions in the FZ and HAZ, which are affected by dilution, as shown in Fig. 6. It is also noteworthy that both transverse and longitudinal stress predictions for actual dilution present highly irregular distributions, which can be attributed to the significant variations in microstructure between the weld metal and the base material and between the as-deposited and reheated weld metals (Figs. 6-8). 
Transverse stress (S11) Longitudinal stress (S33)
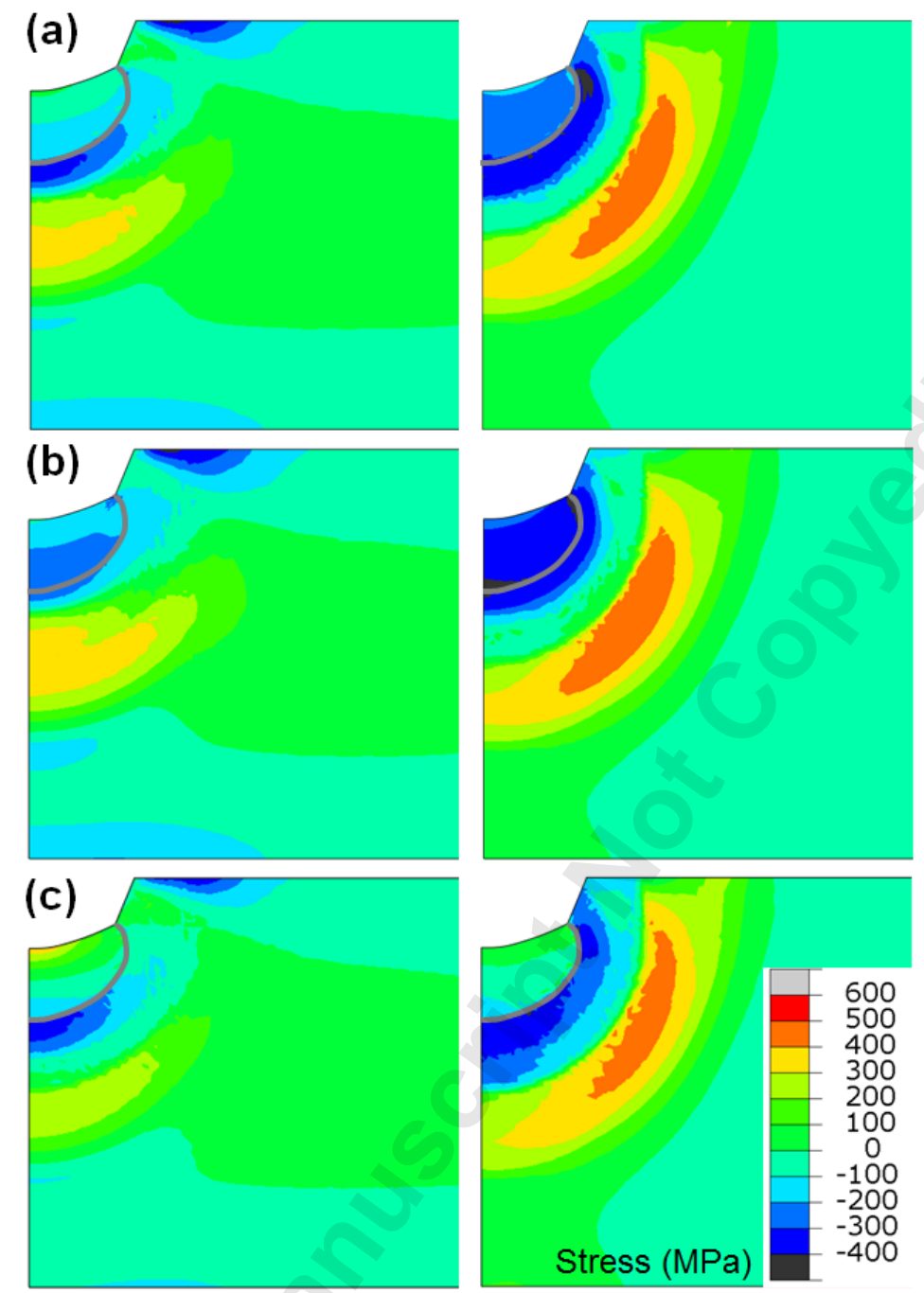

Fig. 12. Predicted residual stresses after one pass: (a) $\mathrm{D}_{1}=0.44, \mathrm{D}_{2}=0.17, \mathrm{D}_{3}=0.09$; (b) $\mathrm{D}_{1}=\mathrm{D}_{2}=$ $\mathrm{D}_{3}=1 ;$ (c) $\mathrm{D}_{1}=\mathrm{D}_{2}=\mathrm{D}_{3}=0$. Solid grey line indicates the fusion boundary. 


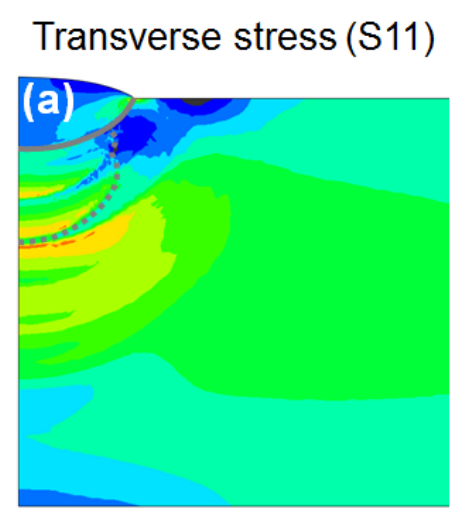

Longitudinal stress (S33)
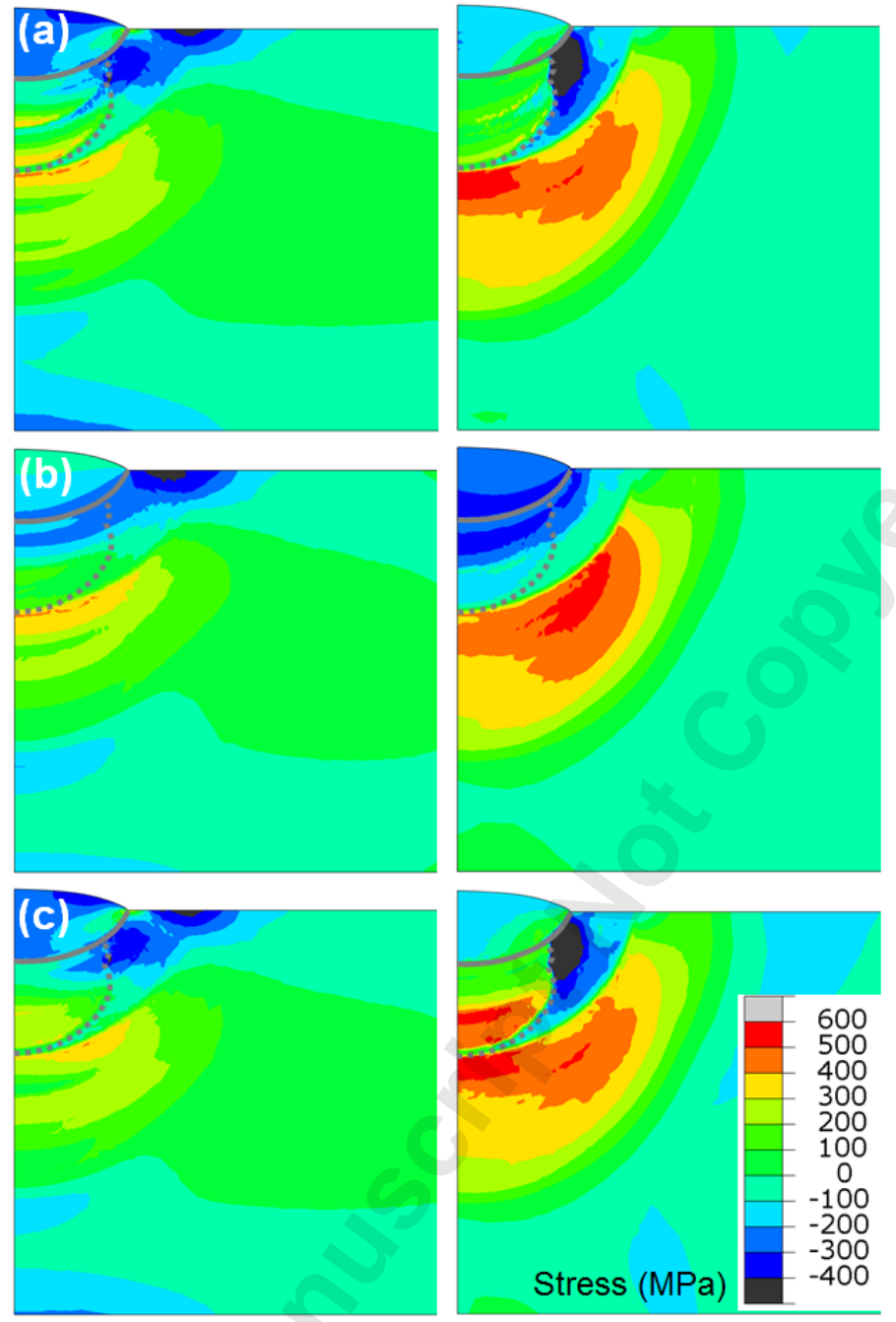

Fig. 13. Predicted residual stresses after three passes: (a) $\mathrm{D}_{1}=0.44, \mathrm{D}_{2}=0.17, \mathrm{D}_{3}=0.09$; (b) $\mathrm{D}_{1}=\mathrm{D}_{2}$ $=\mathrm{D}_{3}=1$; (c) $\mathrm{D}_{1}=\mathrm{D}_{2}=\mathrm{D}_{3}=0$. Solid and dashed grey lines indicate the current and accumulated fusion boundaries, respectively.

\section{Concluding remarks}

A 2D finite element model has been developed to investigate the thermal, metallurgical and mechanical behaviour of a three-pass gas tungsten arc weld in SA508 Gr.3 Cl.1 steel. The dilution was determined by analysing the predicted fusion zones for individual passes. The numerical predictions for temperature, microstructure, hardness and residual stress were compared with experimental results obtained in previous studies [16, 17]. The modelling results demonstrated that 
dilution has significant effects on the final microstructure of the weld metal and the residual stresses in the weldment. Since SA508 steel has a higher hardenability than the SD3 filler material, the weld metal is prone to martensite formation at high dilution values, which implies that an increase in dilution leads to higher weld metal hardness. This metallurgical influence should be considered in modelling. The residual stresses in the weld metal tend to be less tensile or more compressive when the dilution increases. This behaviour is associated with the tendency for delayed austenite decomposition, and the ferritic phase transformations (e.g. martensite transformation) taking place at lower temperatures in highly diluted weld metal. The introduction of transformation strains at lower temperatures can effectively counteract the thermal contraction during cooling, thereby suppressing tensile stresses and promoting compressive stresses in the weld region. This leads to an increase in equilibrating tensile stresses in the HAZ and adjacent base material.

\section{Acknowledgments}

The authors gratefully acknowledge the funding support from EPSRC grant EP/J021172/1, for the development and characterisation of welds under the NNUMAN programme. The assistance given by the IT Services and the use of the Computational Shared Facility at the University of Manchester are acknowledged. The authors are also grateful to P. Bendeich, S. Bate, P. Hurrell and D.W. Rathod for their help and comments.

\section{References}

[1] J.A. Francis, H.K.D.H. Bhadeshia, P.J. Withers. Welding residual stresses in ferritic power plant steels, Materials Science and Technology 23 (2007) 1009-1020.

[2] P. Withers. Residual stress and its role in failure, Reports on progress in physics 70 (2007) 2211.

[3] T. Wang. A continuum damage model for ductile fracture of weld heat affected zone, Engineering Fracture Mechanics 40 (1991) 1075-1082.

[4] B. Jeyaganesh, M. Callaghan, J. Francis, P. English, A. Vasileiou, M. Roy, W. Guo, N. Irvine, M. Smith, L. Li, A.H. Sherry. Overview of Welding Research Under the New Nuclear Manufacturing (NNUMAN) Programme. ASME 2014 Pressure Vessels and Piping Conference: American Society of Mechanical Engineers, 2014.

[5] M.C. Smith, A.N. Vasileiou, D.W. Rathod, J. Francis, N. Irvine, Y. Sun. A review of welding research within the new nuclear manufacturing (NNUMAN) programme. Proceedings of ASME 2017 Pressure Vessels and Piping Conference. Hawaii, USA, 2017. 
[6] J.C. Feng, D.W. Rathod, M.J. Roy, J.A. Francis, W. Guo, N.M. Irvine, A.N. Vasileiou, Y.L. Sun, M.C. Smith, L. Li. An evaluation of multipass narrow gap laser welding as a candidate process for the manufacture of nuclear pressure vessels, International Journal of Pressure Vessels and Piping 157 (2017) 43-50.

[7] D.W. Rathod, J.A. Francis, M.J. Roy, G. Obasi, N.M. Irvine. Thermal cycle-dependent metallurgical variations and their effects on the through-thickness mechanical properties in thick section narrow-gap welds, Materials Science and Engineering: A 707 (2017) 399-411.

[8] J.N. DuPont, A.R. Marder. Dilution in single pass arc welds, Metallurgical and Materials Transactions B 27 (1996) 481-489.

[9] A. Hunt, A. Kluken, G. Edwards. Heat input and dilution effects in microalloyed steel weld metals, Welding Journal-New York- 73 (1994) 9-s.

[10] L. Halbauer, A. Buchwalder, R. Zenker, H. Biermann. The influence of dilution on dissimilar weld joints with highalloy TRIP/TWIP steels, Welding in the World 60 (2016) 645-652.

[11] T. Ramjaun, H. Stone, L. Karlsson, J. Kelleher, S. Ooi, K. Dalaei, J. Rebelo Kornmeier, H. Bhadeshia. Effects of dilution and baseplate strength on stress distributions in multipass welds deposited using low transformation temperature filler alloys, Science and Technology of Welding and Joining 19 (2014) 461-467.

[12] Y.L. Sun, G. Obasi, C.J. Hamelin, A.N. Vasileiou, T.F. Flint, J. Balakrishnan, M.C. Smith, J.A. Francis. Effects of dilution on alloy content and microstructure in multi-pass steel welds, Journal of Materials Processing Technology 265 (2019) 71-86.

[13] H. Dai, R. Moat, P. Withers. Modelling the interpass temperature effect on residual stress in low transformation temperature stainless steel welds. ASME 2011 Pressure Vessels and Piping Conference: American Society of Mechanical Engineers, 2011. p.1451-1458.

[14] L. Novotný, H.F.G. de Abreu, H.C. de Miranda, M. Béreš. Simulations in multipass welds using low transformation temperature filler material, Science and Technology of Welding and Joining 21 (2016) 680-687.

[15] Y. Rong, J. Xu, Y. Huang, G. Zhang. Review on finite element analysis of welding deformation and residual stress, Science and Technology of Welding and Joining 23 (2018) 1-11.

[16] A. Mark, J. Francis, H. Dai, M. Turski, P. Hurrell, S. Bate, J. Kornmeier, P. Withers. On the evolution of local material properties and residual stress in a three-pass SA508 steel weld, Acta Materialia 60 (2012) 3268-3278.

[17] B.M. Pellereau, C.M. Gill, M. Dawson, P.R. Hurrell, J. Francis, A. Mark. Finite element modelling and measurements of residual stress and phase composition in ferritic welds. ASME 2010 Pressure Vessels and Piping Division/K-PVP Conference: American Society of Mechanical Engineers, 2010. p.1385-1392.

[18] Ş. Talaş. The assessment of carbon equivalent formulas in predicting the properties of steel weld metals, Materials \& Design 31 (2010) 2649-2653.

[19] S. Sarkani, V. Tritchkov, G. Michaelov. An efficient approach for computing residual stresses in welded joints, Finite Elements in Analysis and Design 35 (2000) 247-268.

[20] C.J. Hamelin, O. Muránsky, P. Bendeich, K. Short, L. Edwards. Predicting solid-state phase transformations during welding of ferritic steels. Materials Science Forum, vol. 706: Trans Tech Publ, 2012. p.1403-1408.

[21] R. Smith. FEAT-WMT: Weld-modelling tool user guide, FEATWMT: weld-modelling tool user guide: FeatPlus Limited (2018).

[22] C.J. Hamelin, O. Muránsky, M.C. Smith, T.M. Holden, V. Luzin, P.J. Bendeich, L. Edwards. Validation of a numerical model used to predict phase distribution and residual stress in ferritic steel weldments, Acta Materialia 75 (2014) 1-19.

[23] S.W. Ooi, J.E. Garnham, T.I. Ramjaun. Review: Low transformation temperature weld filler for tensile residual stress reduction, Materials \& Design 56 (2014) 773-781.

[24] J.A. Francis, M. Turski, P.J. Withers. Measured residual stress distributions for low and high heat input single weld beads deposited on to SA508 steel, Materials Science and Technology 25 (2009) 325-334.

[25] A.N. Vasileiou, M.C. Smith, J. Balakrishnan, J.A. Francis, C.J. Hamelin. The impact of transformation plasticity on the electron beam welding of thick-section ferritic steel components, Nuclear Engineering and Design 323 (2017) 309316.

[26] J. Kirkaldy, D. Venugopalan. Prediction of microstructure and hardenability in low-alloy steels, Phase Transformations in ferrous alloys (1983) 125-148.

[27] M.V. Li, D.V. Niebuhr, L.L. Meekisho, D.G. Atteridge. A computational model for the prediction of steel hardenability, Metallurgical and Materials transactions B 29 (1998) 661-672.

[28] D.P. Koistinen, R.E. Marburger. A general equation prescribing the extent of the austenite-martensite transformation in pure iron-carbon alloys and plain carbon steels, Acta Metallurgica 7 (1959) 59-60.

[29] K. Andrews. Empirical formulae for the calculation of some transformation temperatures, Journal of the Iron and Steel Institute 203 (1965) 721-727. 
[30] C. Kung, J. Rayment. An examination of the validity of existing empirical formulae for the calculation of Ms temperature, Metallurgical Transactions A 13 (1982) 328-331.

[31] N. O'Meara, H. Abdolvand, J.A. Francis, S.D. Smith, P.J. Withers. Quantifying the metallurgical response of a nuclear steel to welding thermal cycles, Materials Science and Technology 32 (2016) 1517-4532.

[32] J.B. Leblond, J. Devaux. A new kinetic model for anisothermal metallurgical transformations in steels including effect of austenite grain size, Acta Metallurgica 32 (1984) 137-146.

[33] H. Pous-Romero, I. Lonardelli, D. Cogswell, H.K.D.H. Bhadeshia. Austenite grain growth in a nuclear pressure vessel steel, Materials Science and Engineering: A 567 (2013) 72-79.

[34] C. Henwood, M. Bibby, J. Goldak, D. Watt. Coupled transient heat transfer-microstructure weld computations (Part B), Acta Metallurgica 36 (1988) 3037-3046.

[35] J.-B. Leblond, G. Mottet, J. Devaux, J.-C. Devaux. Mathematical models of anisothermal phase transformations in steels, and predicted plastic behaviour, Materials science and technology 1 (1985) 815-822.

[36] G.I. Rees, H.K.D.H. Bhadeshia. Thermodynamics of acicular ferrite nucleation, Materials Science and Technology 10 (1994) 353-358.

[37] Y.L. Sun, G. Obasi, C.J. Hamelin, A.N. Vasileiou, T.F. Flint, J.A. Francis, M.C. Smith. Characterisation and modelling of tempering during multi-pass welding, Journal of Materials Processing Technology 270 (2019) 118-131.

[38] J.A. Francis, H.J. Stone, S. Kundu, H.K.D.H. Bhadeshia, R.B. Rogge, P.J. Withers, L. Karlsson. The Effects of Filler Metal Transformation Temperature on Residual Stresses in a High Strength Steel Weld, Journal of Pressure Vessel Technology 131 (2009) 041401-041408. 